\title{
Is there an evidence base for intuition and empathy? The risks and benefits of inviting an older person to discuss unresolved loss
}

Ed Peile Aston Clinton Surgery, Aston Clinton, Buckinghamshire, UK

\begin{abstract}
This paper relates a common problem in community practice. A client chose to share information with a support worker who was unsure of her competence to deal with the disclosure. An innovative and reflective approach to finding evidence for potential benefit or harm is described, together with an interpretation of this evidence, and finally recommendations for clinical practice based on 'best available evidence'.
\end{abstract}

Key words: bereavement; counselling; disclosure; empathic listening; evidencebased practice

\section{Introduction}

This paper arose out of a case discussion in which a support worker, who had recognized that an older client might still be grieving about something that had happened a long time ago, invited her client to talk about this 'unresolved loss'. A long, emotional description of the event and the pain it had caused was shared between the patient and the support worker. It seemed to be helpful but, quite appropriately, the helper was concerned: 'I've not been trained as a counsellor. Should I have done that? Could I have done more harm than good?'

\section{The problem}

Counsellors and psychotherapists are trained to help patients and clients to talk through painful past experiences, and there is good evidence of the potential therapeutic benefit of this. However, without formal counselling training, what should primary care workers do when they encounter a patient with a painful memory that may be detrimental to health?

Address for correspondence: Dr Ed Peile, Chiltern Waters, 1 Stablebridge Road, Aston Clinton, Bucks HP22 5ND, UK. Email: edpeile@msn.com

(C)Arnold 2000
Should we take the opportunity to invite the patient to talk about it? Or could we do more harm than good by lifting the lid off the can of worms when we don't know what to do with the worms? Bringing a problem to the surface is not the same as resolving it, but is the process more likely to help the patient to move forward, or to increase their emotional burden?

These are important questions for a holistic care approach. Randomized controlled trials are unlikely to provide an answer. We therefore have to look broadly at the health and psychosocial literature in order to inform our practice.

\section{An approach to "best evidence"}

There may not be a satisfactory answer to this type of question in the literature (I certainly could not find one), but that does not mean that an evidencebased approach has to be abandoned. Indeed, far from it, as the approach has to be somewhat innovative if one is going to find and interpret 'best evidence'. I shall describe here the approach which I adopted.

My question was eventually formulated as follows. 'Does an opportunity to talk about unresolved loss to an empathic caregiver (untrained in counselling) change health or psychological wellbeing in older depressed patients?' I searched 1463-4236(2000)PC0130A 
Medline, Embase, Psyclit, Cinahl and Sociofile using both Winspirs and Ovid, for the following search terms: reminiscence; life review; communication; listening; empathy; depression; counselling; psychotherapy; social support; caregiving; confidant; bereavement. In addition to the references I found through searches, discussions with colleagues led me to a number of other useful books and sources, all of which were critically appraised.

I then employed a process of deduction, first constructing the relevant assertions which I felt were supported by the available evidence, and then linking these assertions into a circuit around the central question. I picture each assertion as a segment which never quite reaches the central core (see Figure 1), but each segment provides a different angle of approach to the core question, and to have examined each segment in turn is to have taken a tour around the central question, getting ever closer to a 'best answer'.

1) A confidant is an important element of a social support system (Murphy, 1982; Oxman et al., 1992; Potts, 1997).

2) A social support system is important for elders to progress healthily through bereavement (Hays et al., 1994, 1998).

3) Unresolved loss may contribute to depression in older people (Glass et al., 1997).

4) Depression adversely affects health and wellbeing in older people (Hays et al., 1997; Smits et al., 1997).

5) Psychotherapy and counselling can be beneficial for depressed elders (Brodaty and

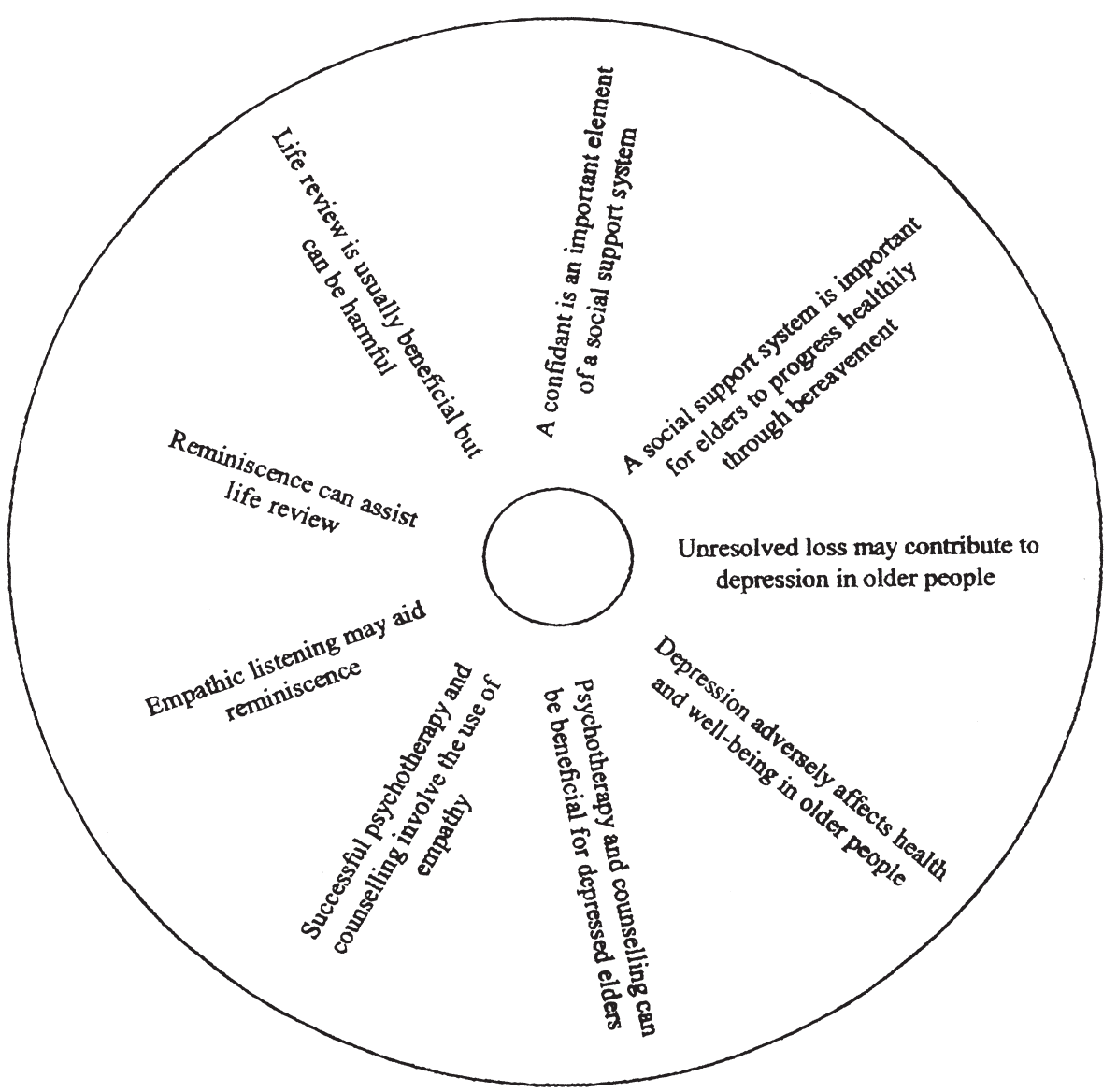

Figure 1 Assertion steps individually supported by evidence.

Primary Health Care Research and Development 2000; 1: 71-77 
Andrews, 1983; Scogin and McElreath, 1994; Landreville and Gervais, 1997).

6) Successful psychotherapy and counselling involve the use of empathy (Olson, 1995).

7) Empathic listening may aid reminiscence (Solomon, 1974; Maguire, 1985).

8) Reminiscence can assist life review (McMahon and Rhudick, 1964; Thornton and Brotchie, 1987).

9) Life review is usually beneficial, but can be harmful (Butler, 1963; Gillies and James, 1978; Pennebaker et al., 1988; Parkes, 1997).

\section{Box 1 A selective look at some of the relevant evidence}

- How do (older) people deal with emotional traumas?

- What is the role of talking about past painful experiences?

- Who is the appropriate confidant for someone who needs to talk?

- What harm can talking cause?

The evidence which I found supports the premise that it is generally helpful to encourage an older person to talk about unresolved loss, even if one is not a trained counsellor, but there are important caveats that life review may be harmful.

\section{How do (older) people deal with emotional traumas?}

Colin Murray Parkes (Parkes, 1997) reminds us that, following the death of a close loved one, the world of the griever is an upside-down world. It looks familiar but feels unfamiliar because the person who has died was a central part of the 'model' of the world which we all unconsciously carry in our heads. This explains why older people may become confused in their grief and may withdraw from a world which now seems strange to them.

Psychotherapists have debated the notion of a healthy grieving process, and have looked at what can go wrong if painful, unresolved experiences are initially suppressed and pushed to the back of the mind. They may only become apparent because of physical symptoms such as muscle tension and pain, or perhaps as disturbances of behaviour, or flashbacks. When these symptoms occur it is often too painful to talk about the experiences, but eventually, with help, people can begin to sort out even painful experiences in their minds, and start to look at the experience from a safe distance.

The psychotherapeutic term 'assimilation' refers to the situation where a person is eventually able to look back on and discuss a painful experience in their past in a healthy way which acknowledges that 'this happened to me but I've now moved on'. When the process is not going very well the sufferer tends to 'ruminate' about their pain. To dwell on it consciously and unconsciously, and the very passage of time itself, can make the situation more painful (Pennebaker et al., 1988; Rimé, 1995; Stiles, 1995).

\section{What is the role of talking about past painful experiences?}

There is good evidence that talking helps. Scientific experiments have been conducted in which people were encouraged to write or talk about the painful experiences in their past, and the evidence suggests that when they discussed their feelings in a meaningful way this helped to promote wellbeing and reduce depression. However, there is a risk that for some people 'rehearsing' or endless repetition of their grief out loud may just be like a form of unhealthy rumination. They may talk about their pain to others in the same unhelpful way as they ruminate internally (Rimé, 1995).

Individuals differ greatly, and Coleman (1986) has identified four different ways in which older people reminisce.

- Group 1 enjoy reminiscing, and it helps to keep their spirits high.

- Group 2 reminisce compulsively because they have a past full of troubles, and this increases their depression and anxiety.

- Group 3 have no need to reminisce, as they are already quite positive, and they prefer to talk about the present and the future.

- Group 4 do not like to talk about the past because it reminds them of what they have now 
lost, in the sense that the present seems much less fulfilling than in days gone by.

It is important to remember that Coleman's work concerned the topic of general reminiscence, not talking about painful memories or unresolved losses. However, if we bear his categories in mind, it may help our intuition as to whether talking about pain is likely to be helpful. Fortunately, most patients are likely to be of the group 1 type, and giving them an opportunity to talk is probably helpful as, on the whole, they are comfortable about going back to their past. Group 3 patients are unlikely to need a listening ear for past pain, so it is the group 2 and group 4 patients whom we need to worry about. We should try to avoid either reinforcing someone's anxiety by yet another rehearsal of already well-vented painful experiences, or encouraging people to return to their past, if in so doing, we serve to remind them of all that they have lost, and thus make the present less tolerable for them.

\section{It may help to talk to someone, but who should be the confidant?}

There is a great deal of information in the social sciences and psychology literature about the social networks of older people and the individuals they choose to be their confidants. It appears that this is an area where there is a very real change with age. In younger age and in mid-life we are often fortunate enough to have many friends and family members, and from this wide circle we choose special people whom we trust as our confidants. When we reach very old age, the circle narrows, many people will have died, and it is not so easy to get out and about or to keep up with old friends. Family may still be important, but they are often not used by older people as their confidants (Connidis and Davies, 1990, 1992; Hays et al., 1997).

'In this network of friends a new class of friends becomes important. These are the helpers - those who provide paid or volunteer services to typically house-bound or bed-fast adults' (Johnson and Troll, 1994). This has been examined in detail in an in-depth UK survey of older people. In total, $82 \%$ of those who had a home help named that person as their confidant. Next in order of preference as a confidant was the district nurse, and then the social worker. Thus closeness of contact becomes important (Keith, 1996).

\section{What harm can talking do?}

Think of the different ways in which people reminisce (see Coleman's groupings above). Pressing those who dislike reminiscing (i.e., group 4) to talk about the past can do more harm than good (Holden and Woods, 1988). Reviewing our past life as we get closer to death can be very helpful if we can reorganize our past experience to give new and significant meaning to our lives, but there are times when this process goes wrong. Under those circumstances, thinking back to past pain just increases our sense of chaos, disorder and feeling lost. I quote from Gillies and James:

Recalling painful memories may be therapeutic and sustain the self-esteem of some old people if they can be helped to remember the ways that they coped in trying situations in the past. However, for those who have deep and unresolved scars, very sensitive handling and personal counselling may be needed. Even in old age unresolved grief can be worked through but psychiatric advice should be sought if there is any doubt about this.

(Gillies and James, 1978)

\section{Suggestions on how to help someone to talk}

An American 'Nursing Standard of Practice Protocol' has recommended:

Nurses should provide emotional support to depressed elderly patients by providing empathic, supportive listening, encouraging patients to express their feelings in a focused manner on issues such as grief or role transition, supporting adaptive coping strategies, identifying and reinforcing strengths and capabilities, maintaining privacy and respect and instilling hope.

(Kurlowicz, 1997)

These are lofty objectives, not always easy for trained nurses to achieve, and I think there is scope 


\section{Box 2 Key points}

- Unresolved grief can be harmful if the patient is unable to move towards a healthy 'assimilation' of the emotional pain.

- Sometimes talking about the pain can remove the block to progress.

- People differ in their use of reminiscence - it may help some and hinder others.

- At different stages in life, people tend to have different confidants - in old age, it is often a professional carer who is chosen as a confidant.

for some practical advice, which is intended for all health-care workers, regardless of their training.

\section{Check out the objectives}

We need to make sure that we are really focusing on the needs of our patient and client, and that we are not just asking out of our own curiosity, but because we believe it may help the patient to talk about past pain.

\section{Centre the conversation on feelings}

When inviting others to talk about their pain, we should help them to feel secure and safe, knowing that we will respect their confidentiality and make it comfortable for them to show their pain, because we are not frightened of the emotions which are so powerful for them.

\section{Time is all important}

Experimental evidence backs up what we probably all know - that it is unhelpful to get someone talking about a part of their life which is very important and occupies much of their thoughts if we will need to cut them off before they have had time to work it through. The helpful aspect of talking is the way in which, as a person talks to someone else, they begin to organize their own thoughts and make order out of chaos. This cannot be done in 5 or 10 minutes. If someone needs to talk, it may be better to say something along the lines of 'Would it help you to talk about this? Shall I make sure that I've got plenty of time when I come back tomorrow so that we can chat about it together?' Rimé's work suggests that 45 minutes is about the length of time that is often needed.

\section{The patient needs safety nets}

1) Sensitivity. If you show someone that you really listen and you really care you are unlikely to do harm, and it is usually possible to check back with them later - for example, 'Do you think it helped to talk about. . .?' Gillies and James expressed it thus:

The old people themselves will almost certainly make it plain if they do not want to be involved even if they no longer find it easy to express themselves clearly. It may become apparent that they don't want to talk about the past when it seems natural to do so, or they may convey their reluctance by their behaviour or attitude.

(Gillies and James, 1978)

2) Referral. Miller (1989) asks: 'Why is a psychotherapist necessary in a world that is literally full of free empathy?' Some people do have a need for in-depth counselling or psychotherapy, and if after having taken the lid off the can of worms, you feel that there is something going on which is really proving damaging to your client or patient, I think you have a duty to refer them for more qualified assessment, perhaps after consulting with your supervisor about a counselling or community psychiatric nurse referral.

\section{You need safety nets}

An important part of your safety net is that you never restrict yourself by impossible guarantees of confidentiality. All professional counsellors have confidential supervisors, and their clients often benefit from a 'second look' at the problem. Although the patient who is divulging sensitive information needs to feel confident that you will not tittle-tattle, never give an undertaking not to talk confidentially to a supervisor or the patient's doctor. Otherwise you may be put in a very difficult situation. Your client's burden may become your burden, and you may need supervision to straighten out your concerns. Your client might also reveal suicidal thinking which it is your clear 
duty, as a health-worker, to share with his or her doctor.

\section{Conclusion}

If you are the type of person who is a natural good listener, you will probably already have experienced how helpful you can be to others when you enable them to talk about their feelings of pain. Take care of yourself and make sure you do not become burdened by the emotional loads of other people. You may find that you want to develop your listening skills, and good training for this is often offered by counselling organizations.

\section{Take-home message}

Even vague, almost intangible questions about our everyday practice can be approached in an evidence-based way. ${ }^{a}$

\section{Box 3 A guide to helping someone to talk about buried pain}

- Check out your motives and the patient's wishes.

- Encourage the patient to talk about their feelings, and make them feel safe to do so.

- Allow plenty of time for them to open up.

- Look after the patient's safety - be sensitive to their needs, and be prepared to refer them on, if that is what they need.

- Look after your own safety and comfort seek professional support and supervision if necessary.

\footnotetext{
${ }^{\mathrm{a} A}$ more complete review of the literature and an evidencebased approach to the question 'Does an opportunity to talk about unresolved loss to an empathic caregiver (untrained in counselling) change health or psychological well-being in older, depressed patients?' are available from the author of this occasional paper (who would welcome feedback and suggestions): Dr Ed Peile, Tel. +44(0)1296 631727, e-mail edpeile@msn.com
}

\section{References}

Brodaty, H. and Andrews, G. 1983: Brief psychotherapy in family practice: a controlled prospective intervention trial. British Journal of Psychiatry 143, 11-19.

Butler, R. N. 1963: The life review: an interpretation of reminiscence in the aged. Psychiatry 26, 65-76.

Coleman, P. 1986: Issues in the therapeutic use of reminiscence with elderly people. In Hanley, I. and Gilhooly, M., editors. Psychological therapies for the elderly. London: Croom Helm, 41-64.

Connidis, I. and Davies, L. 1990: Confidants and companions in later life: the place of family and friends. Journal of Gerontology: Social Sciences 45, S141-149.

Connidis, I. and Davies, L. 1992: Confidants and companions: choices in later life. Journal of Gerontology: Social Sciences 47, S115-22.

Gillies, C. and James, A. 1978: Reminiscence work with old people. London: Chapman \& Hall.

Glass, T. A., Kasl, S. V. and Berkman, L. F. 1997: Stressful life events and depressive symptoms among the elderly: evidence from a prospective community study. Journal of Aging and Health 9, 70-89.

Hays, J. C., Kasl, S. and Jacobs, S. 1994: Past personal history of dysphoria, social support and psychological distress following conjugal bereavement. Journal of the American Geriatrics Society 42, 712-18.

Hays, J. C., Landerman, L. R., George, L. K. et al. 1998: Social correlates of the dimensions of depression in the elderly. Journal of Gerontology: Psychological Sciences 53, P31-39.

Hays, J. C., Saunders, W. B., Flint, E. P. et al. 1997: Social support and depression as risk factors for loss of physical function in late life. Aging and Mental Health 1, 209-20.

Holden, U. P. and Woods, R. T. 1988: Reality orientation psychological approaches to the 'confused' elderly. London: Churchill Livingstone.

Johnson, C. and Troll, L. 1994: Constraints and facilitators to friendships in late life. Gerontologist 34, 79-87.

Keith, P. M. 1996: Formal and informal confidants and well-being of British aged. Journal of Gerontological Social Work 25, 165-83.

Kurlowicz, L. H. 1997: Nursing standard of practice protocol: depression in elderly patients. Geriatric Nursing: American Journal of Care for the Aging 18, 192-200, 243.

Landreville, P. and Gervais, P. W. 1997: Psychotherapy for depression in older adults with a disability: where do we go from here? Aging and Mental Health 1, 197-208.

Maguire, P. 1985: Barriers to psychological care of the dying. British Medical Journal 291, 1711-13.

McMahon, A. W. and Rhudick, P. J. 1964: Reminiscing: adaptational significance in the aged. Archives of General Psychiatry 10, 292-298.

Miller, I. J. 1989: The therapeutic empathic communication (TEC) process. American Journal of Psychotherapy 43, 531-45.

Murphy, E. 1982: Social origins of depression in old age. British Journal of Psychiatry 141, 135-42.

Primary Health Care Research and Development 2000; 1: 71-77 
Olson, J. K. 1995: Relationships between nurse-expressed empathy, patient-perceived empathy and patient distress. Image: Journal of Nursing Scholarship 27, 317-22.

Oxman, T. E., Berkman, L. F., Kasl, S. et al. 1992: Social support and depressive symptoms in the elderly. American Journal of Epidemiology 135, 356-68.

Parkes, C. M. 1997: Bereavement and mental health in the elderly. Reviews in Clinical Gerontology 7, 47-53.

Pennebaker, J., Kiecolt-Glaser, J. and Glaser, R. 1988: Disclosure of trauma and immune function. Health implications for psychotherapy. Journal of Consulting and Clinical Psychology 56, 239-45.

Potts, M. K. 1997: Social support and depression among older adults living alone: the importance of friends within and outside of a retirement community. Social Work: Journal of the National Association of Social Workers 42, 348-62.

Rimé, B. 1995: Mental rumination, social sharing and the recovery from emotional exposure. In Pennebaker, J. W., editor.
Emotion disclosure and health. Washington, DC: American Psychological Association, 271-91.

Scogin, F. and McElreath, L. 1994: Efficacy of psychosocial treatments for geriatric depression: a quantitative review. Journal of Consulting and Clinical Psychology 62, 69-74.

Smits, C. H. M., Deeg, D. J. H. and Jonker, C. 1997: Cognitive and emotional predictors of disablement in older adults. Journal of Aging and Health 9, 204-21.

Solomon, J. G. 1974: Letter: therapeutic one-way communication. American Journal of Psychiatry 131, 107-8.

Stiles, W. B. 1995: Disclosure as a speech act: is it psychotherapeutic to disclose? In Pennebaker, J. W., editor. Emotion disclosure and health. Washington, DC: American Psychological Association, 71-91.

Thornton, S. and Brotchie, J. 1987: Reminiscence: a critical review of empirical literature. British Journal of Clinical Psychology 26, 93-111. 